\title{
Resenhando autoras negras: feministas, plurais e diaspóricas
}

\author{
Reviewing Black Authors: Feminists, Plurals, and Diasporic
}

\author{
Alexandra Lima da Silva ${ }^{1}$ \\ Sarah Soanirina Ohmer ${ }^{2}$
}

\begin{abstract}
Resumo: Este texto realiza um mapeamento de edições de autoras do pensamento feminista negro dos Estados Unidos e a circulação de tais livros no mercado editorial brasileiro. Procura compreender os significados do movimento de publicação de autoras negras no Brasil. $O$ texto conclui que a emergência da autoria de mulheres negras no Brasil é um processo permeado pelas relações desiguais e pela necessidade de enfrentar lógicas heteronormativas, masculinas e eurocentradas. Resenhar obras de mulheres negras evidência um campo fértil, com repertórios plurais e diaspóricos.
\end{abstract}

Palavras-chave: Autoras Negras; Feminismo Negro; Mercado Editorial; Visibilidade.

Abstract: This article maps out the various U.S. Black Feminist Thought publications translated into portuguese and their circulation in the Brazilian publishing Market. How does the circulation of these texts by Black female authors help to understand the meaning of their scholarhip in a Brazilian context? The article concludes that with the emergence of these Black women's scholarship, it is clear that eurocentric, heteronormative, and male logic needs to be confronted, that the circulation of their work is permeated by systematic inequality, and that reviewing the emerging texts shows there is a fertile, heterogenous, and diasporic field of Black female scholarship.

Keywords: Black Female Authors; Black Feminism; Publishing Market; Visibility.

Submetido em: 08/12/2019 - Aceito em: 19/12/2019 - Publicado em: 28/12/2019.

${ }^{1}$ Doutora em Educação pela UERJ. Professora do Programa de Pós-Graduação em Educação da UERJ. Procientista e Jovem Cientista do Nosso Estado da FAPERJ.

${ }^{2}$ CUNY Lehman College; Assistant Professor; Departments of Latin American Studies and Africana Studies 
Introdução

Após um longo processo histórico de silenciamento, o mercado editorial brasileiro tem demonstrado especial interesse pela autoria de mulheres negras, com destaque para um movimento de tradução de autoras de língua inglesa nascidas nos Estados Unidos. Sem dúvida, tal interesse é fruto das demandas das próprias mulheres negras, que através de diferentes frentes, reivindicam obras que discutam temas relacionados as pautas do feminismo negro. $O$ debate em torno da importância da representatividade e da visibilidade são outros aspectos dignos de nota.

O movimento de tradução de expoentes internacionais do feminismo negro contribuirá de forma substancial na formação de jovens acadêmicas brasileiras, que terão mais oportunidades de acesso a escrita de mulheres negras. Nas últimas décadas, a luta da população negra no Brasil gerou muitas conquistas na área educacional, como a Lei 10.639/03, que torna obrigatório o ensino da história e cultura afro-brasileira e africana em todas as escolas, públicas e particulares, do ensino fundamental até o ensino médio. A institucionalização do sistema de cotas nas universidades públicas foi outro avanço importante para o enfrentamento do racismo estrutural no Brasil.

Tais políticas públicas foram as responsáveis pelo ingresso pessoas negras nas universidades públicas brasileiras, tendo em vista que "estudantes pretos ou pardos passaram a compor maioria nas instituições de ensino superior da rede pública do país (50,3\%), em 2018" (IBGE, 2019). ${ }^{3}$ Contudo, apesar de uma mudança significativa no que tange a presença negra nas universidades brasileiras, professoras negras representam apenas $0,4 \%$ dos Programas de Pós-Graduação no Brasil, conforme indaga a professora Giovana Xavier4.

Como enfrentar a lógica eurocêntrica e construir outras epistemologias na cultura universitária brasileira? Por que a leitura de autoras negras é urgente no Brasil contemporâneo? A existência de mulheres negras nos espaços acadêmicos é pedagógica para todas e todos, assim como o "movimento negro é educador", conforme aprendi com Nilma Lino Gomes (2017). E, segundo a escritora, editora e jornalista Esmeralda Ribeiro, o enfrentamento da lógica eurocêntrica se centra no

\footnotetext{
${ }^{3}$ https://www.ibge.gov.br/estatisticas/sociais/populacao/25844-desigualdades-sociais-porcor-ou-raca.html

${ }^{4}$ Xavier, Giovana. Por que só 0,4\% das professoras doutoras na pós-graduação do Brasil são negras?. Disponível em: $\quad$ https://www.nexojornal.com.br/colunistas/2018/Por-que-s\%C3\%B3-04-das-professoras-doutoras-nap\%C3\%B3s-gradua\%C3\% A7\%C3\%A3o-do-Brasil-s\%C3\%A3o-negras
} 
nosso "poder de mídia, ou seja, nossos mecanismos de divulgação, como internet, redes sociais ou materiais gráficos, são ações importantes para nós." (99; 2014) O mercado editorial e a escrita das mulheres negras é indispensável para mudar a consciência negra brasileira, a consciência negra feminina brasileira, e para que seja refletida a realidade e a demografia brasileira no campo editorial, afirma Ribeiro (1987). A critica literária e professora Fernanda Felisberto, se referindo ao intelectual negro Luis "Cuti" Silva, define o cânone literário em termos de "sob rasura"-cada texto que antes não fazia parte do cânone, e aparece no campo editorial, faz sob rasura no cânone para o transformar e incluir as vozes silenciadas: "torna-se essecial para a desestabilização do cânone a abertura para outras vozes que tencionam o que é ou deve ser literatura" (2014).

A existência de uma bibliografia mais plural, para além dos cânones europeus, com a inclusão de autoras negras de diferentes áreas, também é parte deste movimento formativo. Apesar de ser um investimento tardio por parte do mercado editorial brasileiro, a tradução de obras de autoras fundamentais para o feminismo negro, como bell hooks (2013; 2018; 2019 a; 2019b), Angela Davis (2016; 2017; 2018; 2019), Patrícia Hill Collins (2019), Grada Kilomba (2019), dentre outras, possibilita a democratização do acesso a outras narrativas, para além das eurocentradas ou produzidas exclusivamente por pessoas brancas.

Todavia, é preciso considerar que há certa seletividade no processo de traduções de autoras negras estrangeiras, pois há uma aparente falta de interesse em traduzir autoras afro-latinas no debate. Por que não publicar e traduzir também as companheiras de outras países, com especial atenção, as da América Latina?

É também muito interessante dar visibilidade ao investimento na edição de livros de autoras negras brasileiras, seja pela ação de coletivos, como foi o caso dos livros Beatriz Nascimento: intelectual e quilombola. Possibilidade nos dias de destruição (2018) e Lélia Gonzalez Primavera Para As Rosas Negras (2018), ambos editados pela União dos Coletivos Pan-Africanistas (UCPA), seja em selos independentes, como foi o caso dos livros da coleção Feminismos Plurais, organizada por Djamila Ribeiro ${ }^{5}$. Também é importante ressaltar o investimento realizado pelas

\footnotetext{
${ }^{5}$ https://www.geledes.org.br/coordenada-por-djamila-ribeiro-colecao-feminismos-plurais-e-novidade-dojustificando/
} 
editoras especializadas em cultura negra e diáspora africana, com destaque as obras de autoras como Conceição Evaristo (2014), Sueli Carneiro (2018), Ynaê Lopes dos Santos (2017), Giovana Xavier (2019), apenas para citar algumas.

Ao mesmo tempo em que é importante o investimento na tradução de autoras estrangeiras de língua inglesa, é preocupante que seja algo sazonal, pois em outros momentos, já houve esse movimento, sem a devida continuidade. Por que não incluir mais autoras negras brasileiras na formação das estudantes negras no Brasil, desde a educação básica aos programas de pós-graduação?

\section{Livros que viajam: feminismo negro e mercado editorial no Brasil contemporâneo}

No âmbito do debate sobre pensamento feminista negro, algumas autoras têm merecido maior atenção por parte do mercado editorial brasileiro. Este é o caso de bell hooks. Nascida Gloria Jean Watkins em setembro de 1952, no estado do americano do Kentucky, bell hooks é um ativista, educadora e escritora de muitos livros. Um dos primeiros textos de sua autoria a circular no meio acadêmico brasileiro em língua portuguesa foi "Intelectuais negras", artigo publicado pela revista Estudos Feministas no segundo semestre de 1995. Inspirada nos ensinamentos do educador brasileiro Paulo Freire, ela publicou o livro Teaching to transgress. Education as the practice of freedom (1994) e algumas décadas mais tarde, o livro mereceu uma edição no mercado editorial brasileiro, sendo publicado pela Martins Fontes em 2013 com o título Ensinando a transgredir: a educação como prática da liberdade.

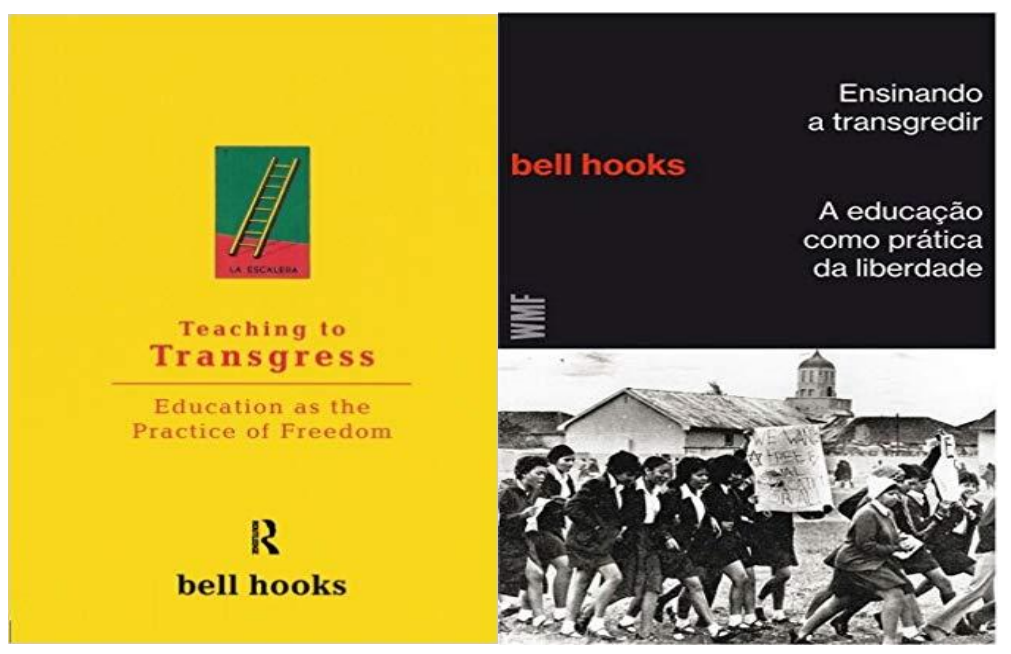


Publicado originalmente no ano 2000, Feminism is for Everybody despertou o interesse da editora Rosa dos Tempos 18 anos depois, e em 2018, foi publicado como O feminismo é para todo mundo: Políticas arrebatadoras. Nas palavras da própria autora, o feminismo é necessário para um mundo mais justo e igualitário, no qual "precisamos acabar com o racismo, o elitismo, o imperialismo" (hooks, 2018, p. 15).

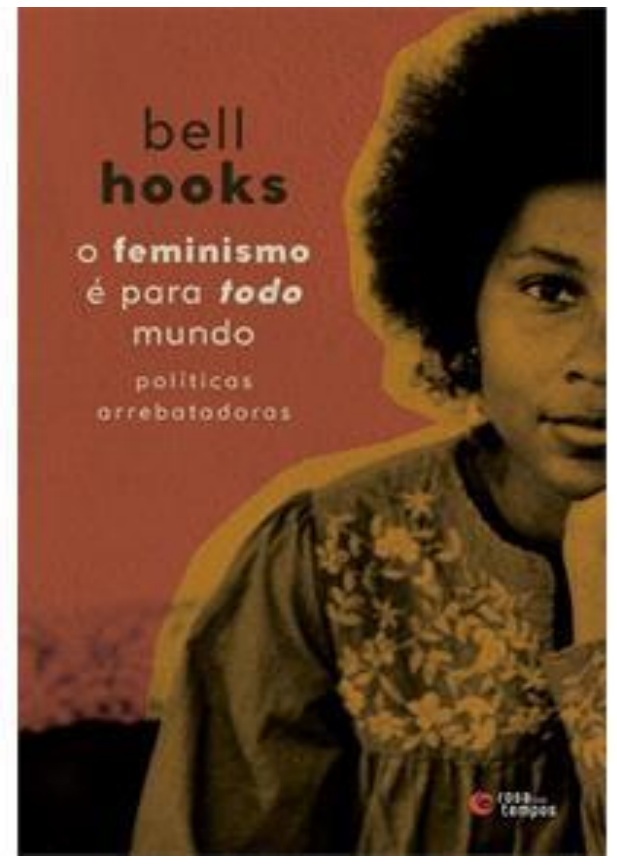

\section{feminism is for everybody}

passionate politics

bell hooks

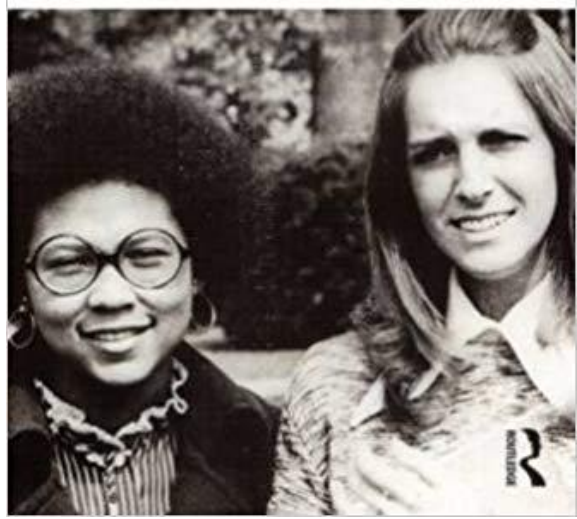

Publicado nos Estados Unidos em 1981 com o título Ain't I a woman? Black women and feminism, a obra foi traduzida e publicada no Brasil pela editora Rosa dos Tempos em 2019, com o título Eu não sou uma mulher? Mulheres negras e feminismo, numa alusão ao icónico discurso de Sojourner Truth no século XIX. 


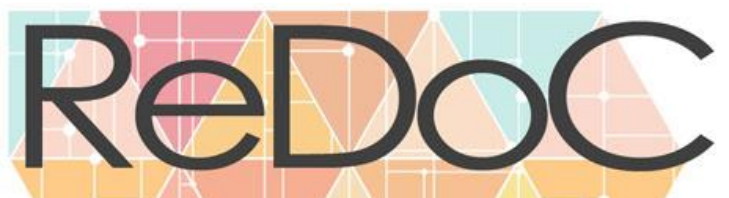

\section{Revista Docência e Cibercultura}

\section{ain't i a woman}

black women and feminism

bell hooks
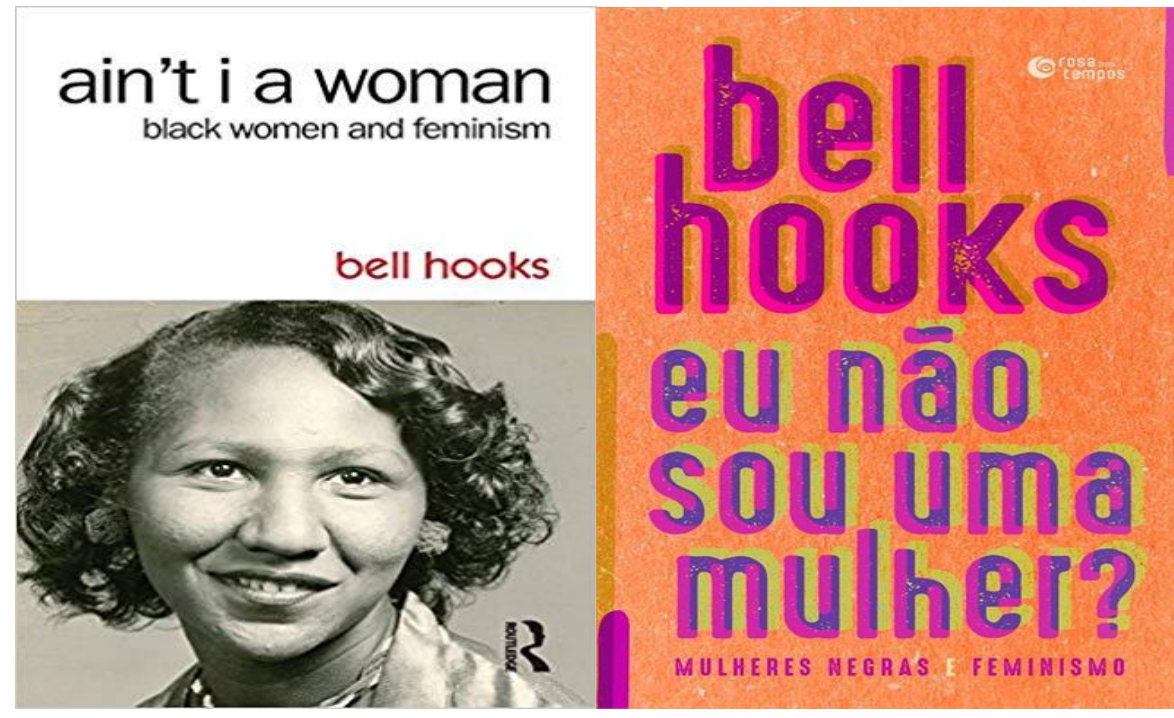

Publicado originalmente em 1984, Feminist Theory: From Margin to Center também mereceu uma edição brasileira de forma bastante tardia. Apenas em 2019, mais de 30 anos depois, foi publicado pela Editora Perspectiva com o título Teoria Feminista: Da margem ao centro.
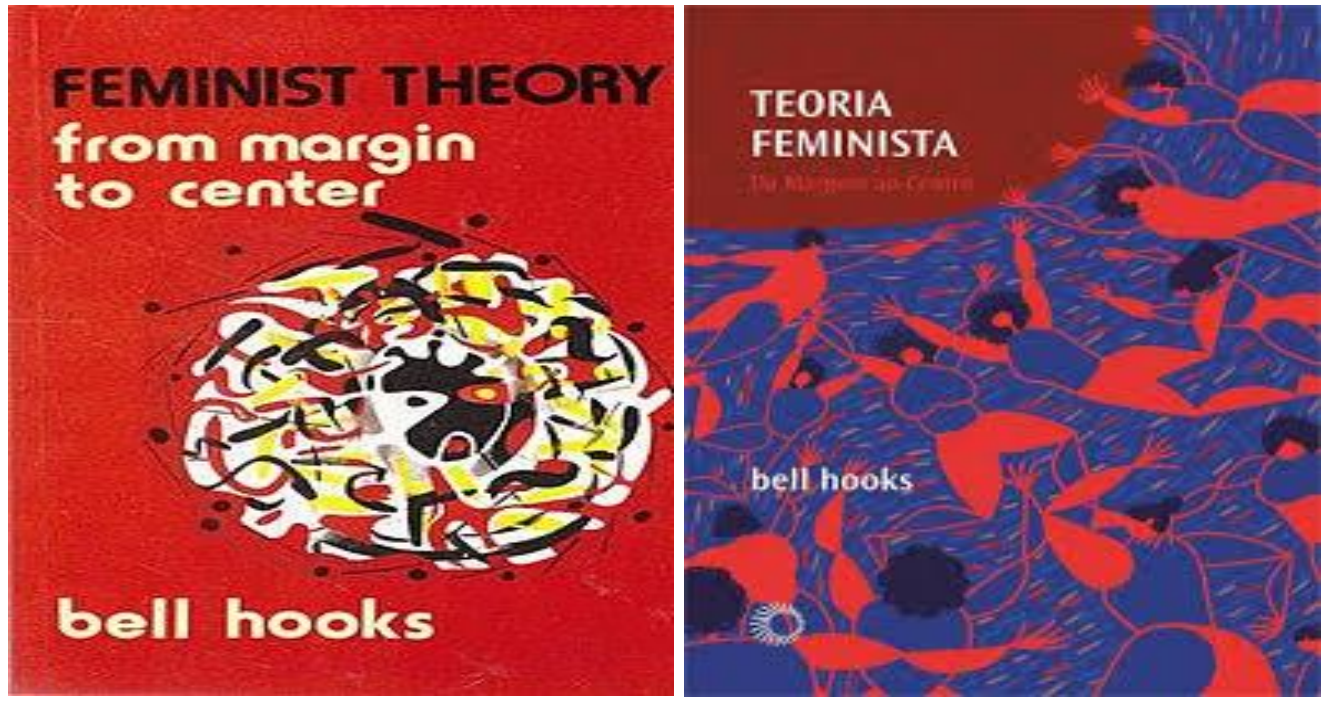


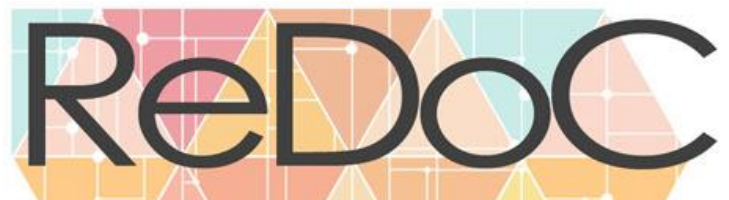

Revista Docência e Cibercultura

A obra de bell hooks também fisgou a editora Elefante, que no ano de 2019 publicou 3 coletâneas de ensaios críticos da autora: Olhares Negros; Erguer a voz e Anseios. Tais livros foram publicados anteriormente com os títulos: Black Looks: Race and Representation (1992); Talking Back: Thinking Feminist, Thinking Black (1989).
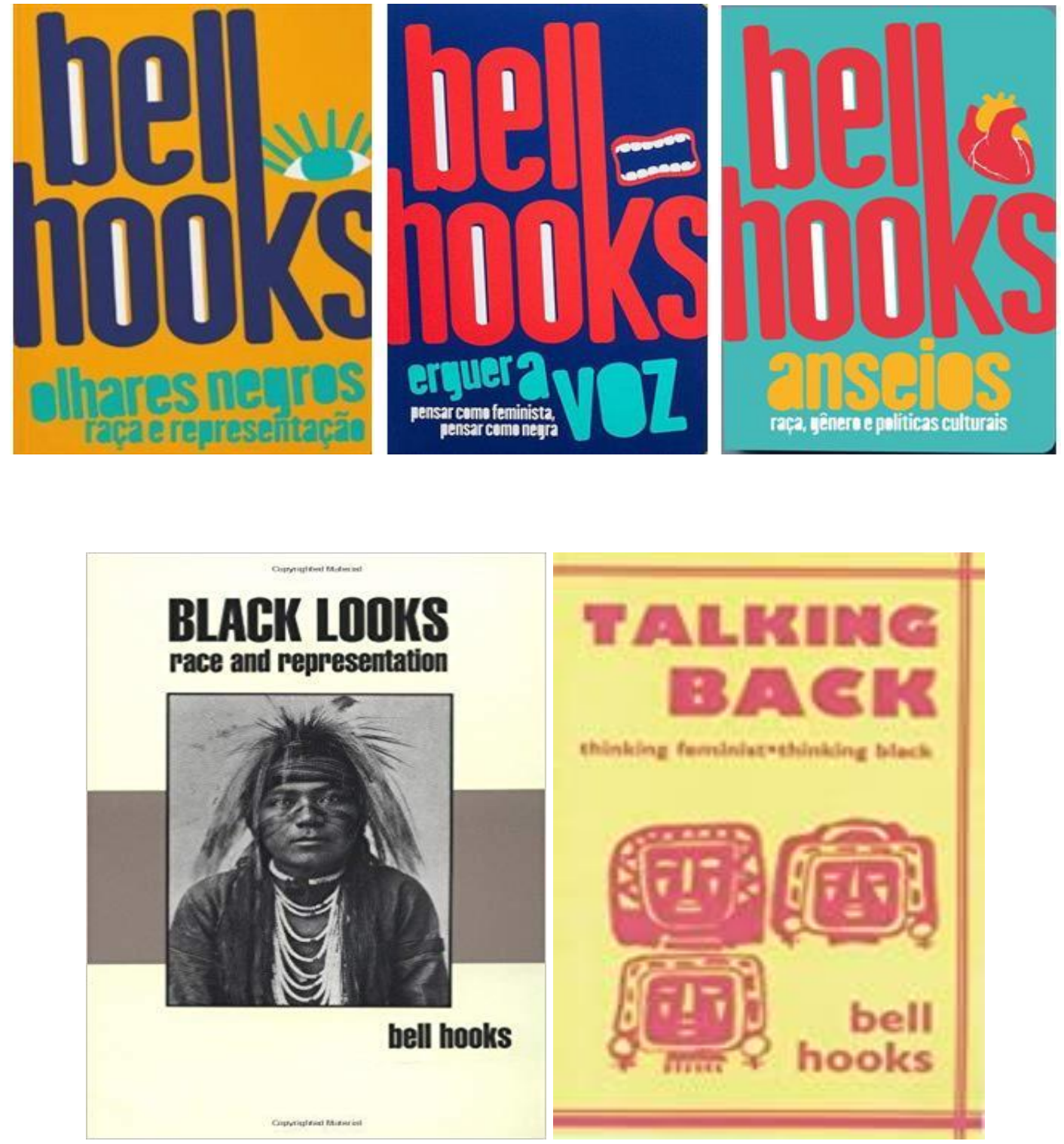
Outra feminista negra dos Estados Unidos e traduzida tardiamente no mercado editorial brasileiro é Angela Davis. Nascida no estado do Alabama em 1944, Angela Davis é internacionalmente conhecida pela militância associada ao partido comunista. Foi professora na Universidade da Califórnia e atualmente defende o abolicionismo no sistema prisional, pois considera que racismo estrutural e encarceramento de massas caminham lado a lado. Publicado em 2005 com o título Abolition democracy: beyong empire, prisions, and torture, a referida obra ganhou uma edição brasileira pela editora Difel em 2009, traduzida como Democracia da Abolição: para além do Império, das prisões e da tortura.
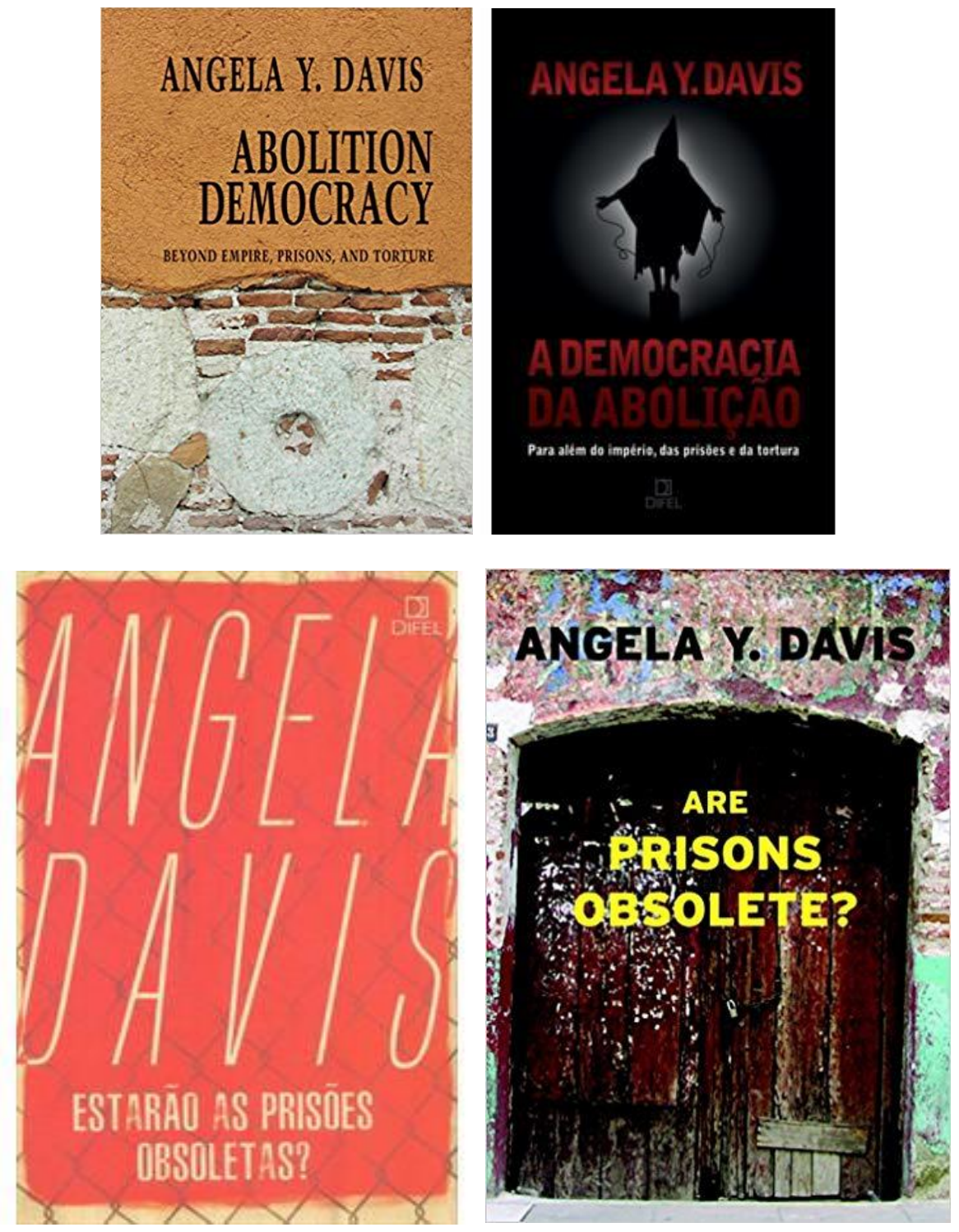


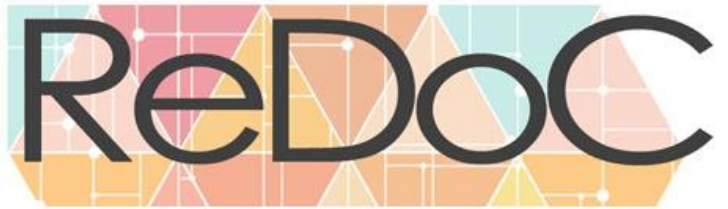

https://doi.org/10.12957/redoc.2019.47165

Revista Docência e Cibercultura

Publicado originalmente em 2003, Are the prisons obsolete? Foi pulicado no Brasil pela editora Difel em 2018 com o título Estarão as prisões obsoletas?

Em 2016, a editora Boitempo iniciou uma série de publicações dos livros de Angela Davis. O primeiro foi clássico Mulheres, raça e classe, publicado originalmente em 1983 (Women, Race, \& Class). Em 2017 a Boitempo publicou Mulheres, cultura e política e em 2018, A liberdade é uma luta constante.
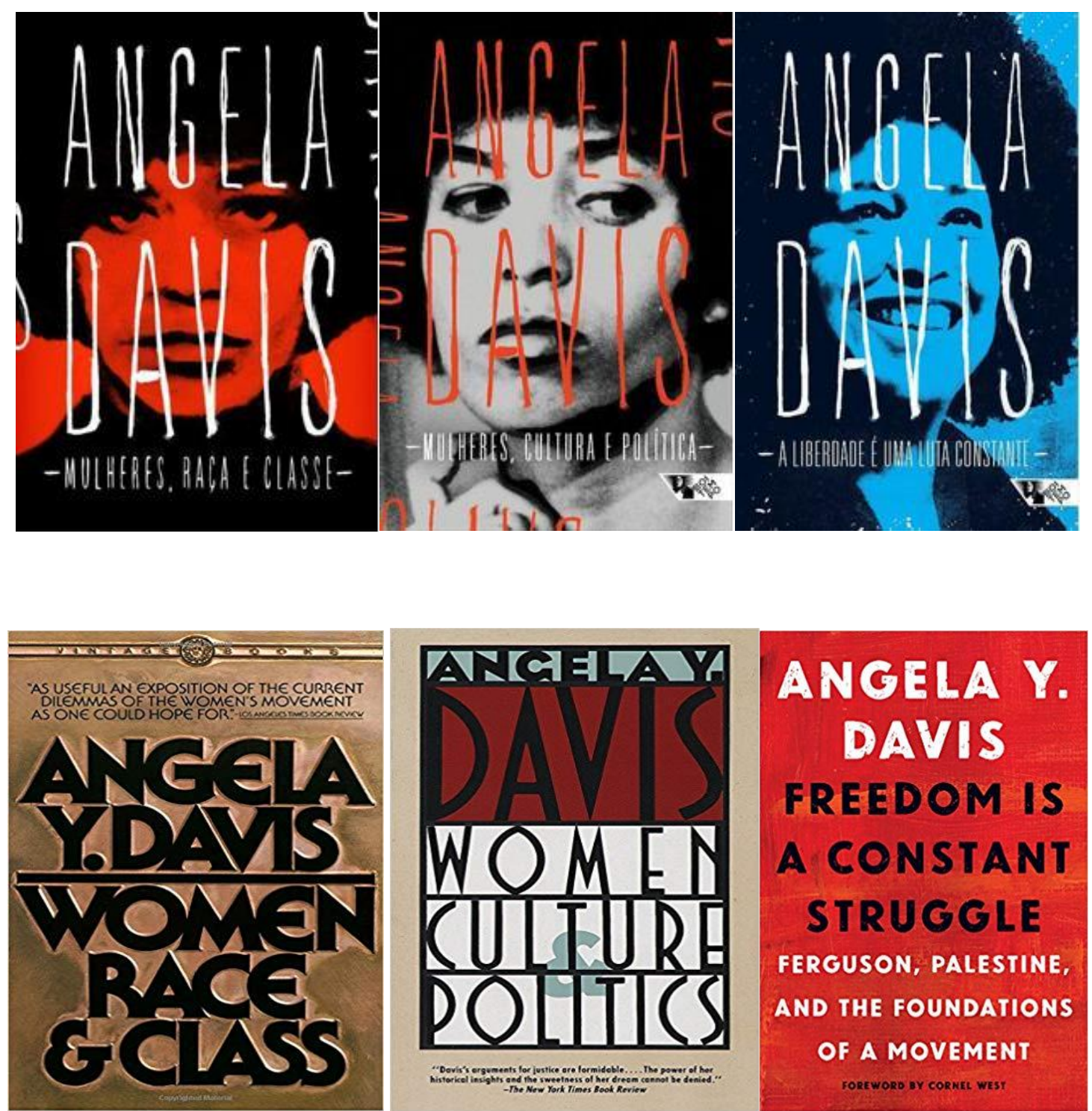

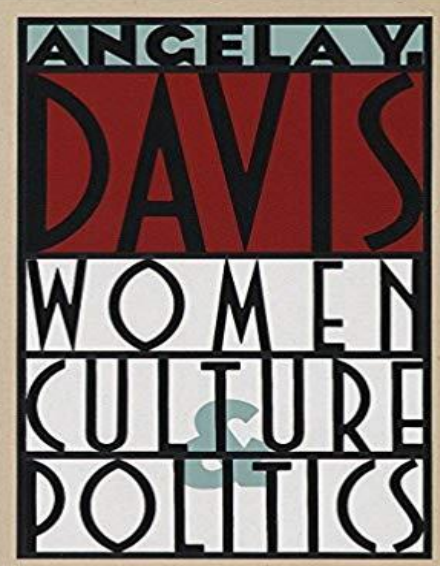

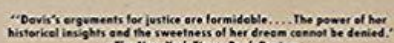

ANGELA Y. DAVIS FREEDOM IS A CONSTANT STRUGGLE FERGUSON, PALESTINE, AND THE FOUNDATIONS

OF A MOVEMENT 
Patrícia Hill Collins é outra referência do feminismo negro nos Estados Unidos publicada recentemente no mercado editorial brasileiro. Nascida na Filadélfia em 1948, Patrícia Hill Collins publicou Feminist Thought: Knowledge, Consciousness, and the Politics of Empowerment em 1990. 0 livro ganhou inúmeros prêmios e a autora coloca em evidência a importância de uma análise interseccional na compreensão do pensamento feminista negro nos Estados Unidos. Apenas em 2019, a importante obra mereceu uma publicação no Brasil, o que foi feito pela editora Boitempo com o título Pensamento Feminista Negro.
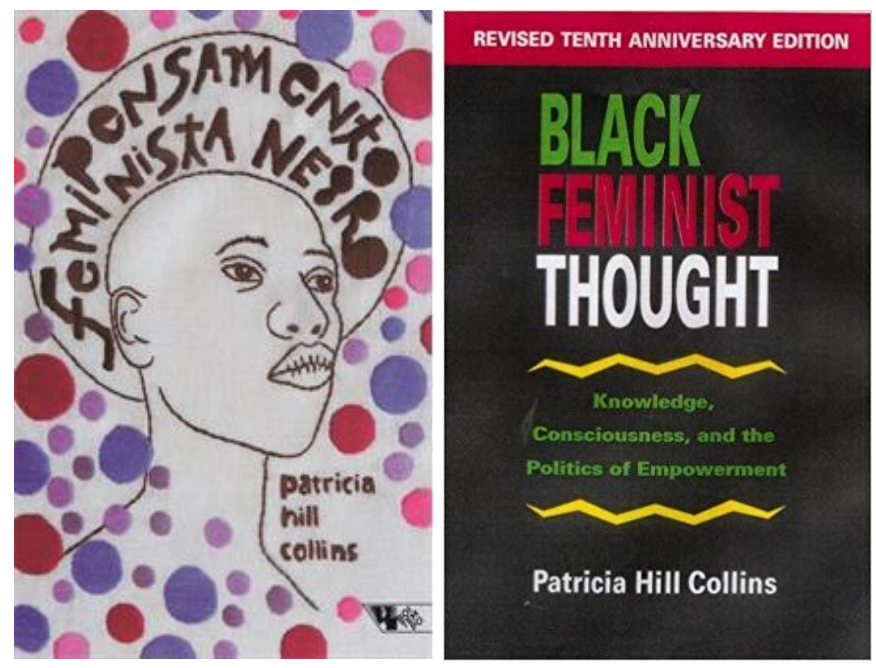

Mulheres negras: escritas plurais

Livros de natureza autobiográfica não são novidade na autoria de mulheres negras, que desde o século XIX já vivenciaram a escrita de si como resistência. Neste vasto universo, destaco algumas obras que mereceram edições no mercado editorial brasileiro.

Nascida na escravidão nos Estados Unidos em 1813, Harriet Ann Jacobs narrou a própria vida no livro Incidents in the Life of a Slave Girl. Written by Herself, publicado originalmente em lingual inglesa, no ano de 1861. A primeira vez que a autobiografia de Harriet Jacobs foi traduzida no Brasil foi no ano do centenário da abolição da escravidão do Brasil (1988), numa publicação da Editora Campus. Alguns anos depois, mereceu nova atenção de editoras brasileiras. Em 2018 a editora Aetia 
publicou Incidentes na vida de uma garota escrava, escritos por ela mesma. Em 2019, a editora, Todavia publicou Incidentes na vida de uma menina escrava.
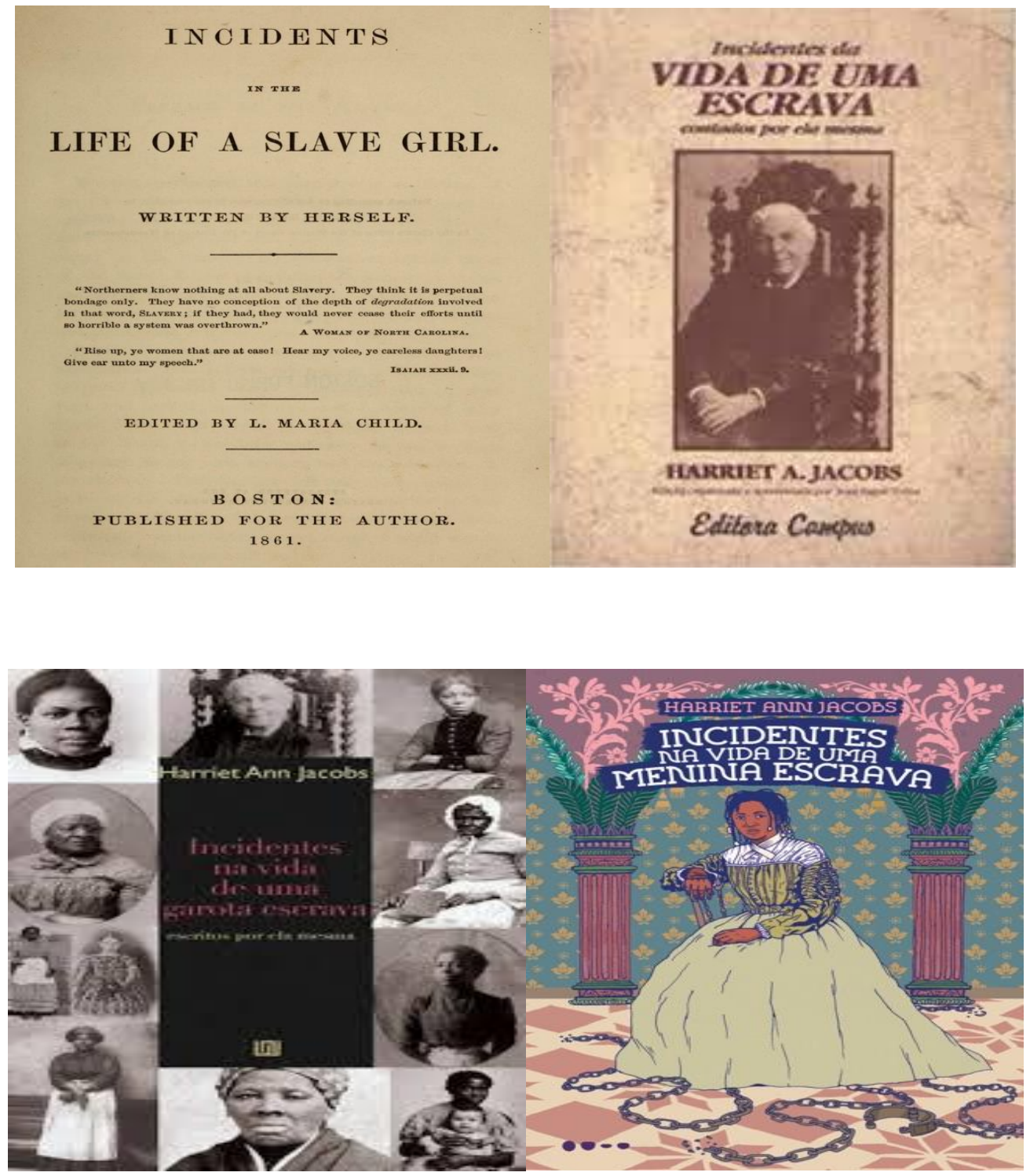

Outra autora renomada autora negra publicada tardiamente no Brasil é Maya Angelou. Nascida Marguerite Johnson, em St. Loius, estado do Missouri em 1928, Maya Angelou foi uma ativista dos direitos civis nos Estados Unidos e poeta. Publicou sua primeira autobiografia em 1969. Apenas em 2018, a autobiografia Eu sei por que o pássaro canta na gaiola foi publicada no Brasil pela editora Astral Cultural. O outro livro autobiográfico de Maya Angelou, Mamãe \& Eu \& Mamãe foi publicado 


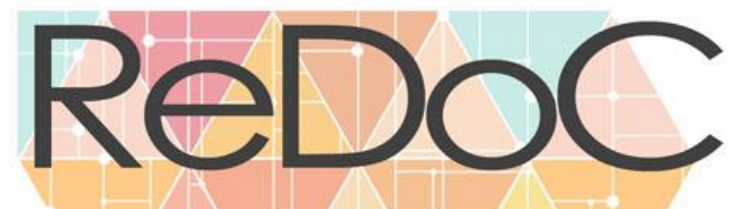

\section{Revista Docência e Cibercultura}

originalmente em inglês no ano de 2013 e em 2018 ganhou edição no Brasil pela editora Rosa dos Tempos.

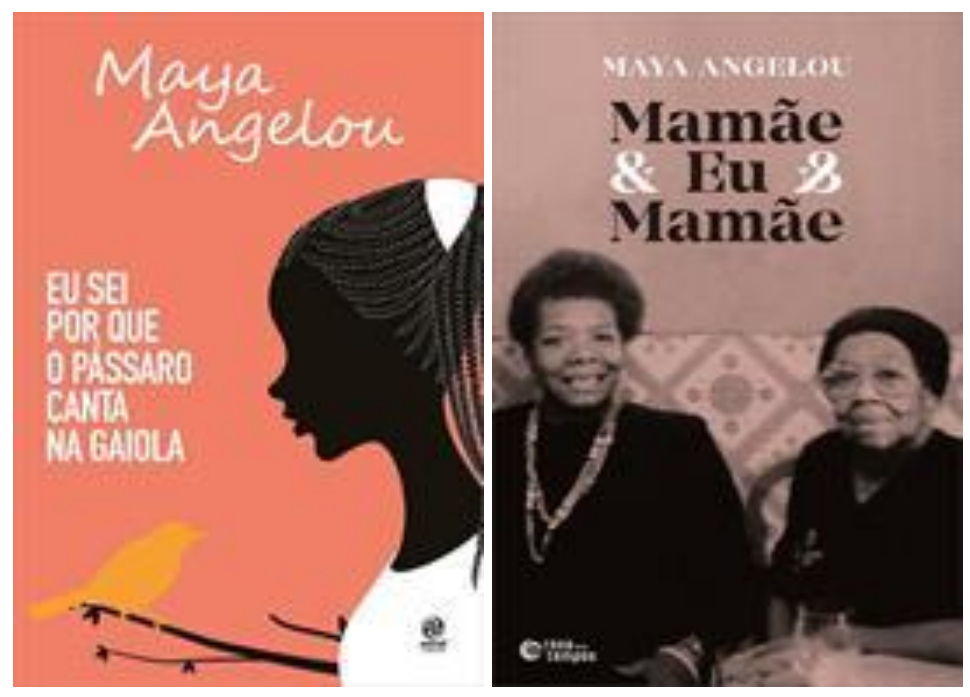

Já a autobiografia de Angela Davis foi publicada nos Estados Unidos em 1975, quando a ativista era bastante jovem, estando no auge de seus 31 anos. Tendo em vista o grande êxito editorial dos livros de Angela Davis no Brasil, a referida autobiografia mereceu uma edição no Brasil em 2019, pela editora Boitempo.

O vasto repertório das autoras negras também inclui a escrita de livros infantis. Neste sentido, destaco os livros A vida não me assusta, de Maya Angelou (2018); Meu crespo é de rainha (2018) e Minha dança tem história (2019), de bell hooks; O que me diz, Louise?( 2014), de Toni Morrison, apenas para citar alguns exemplos.
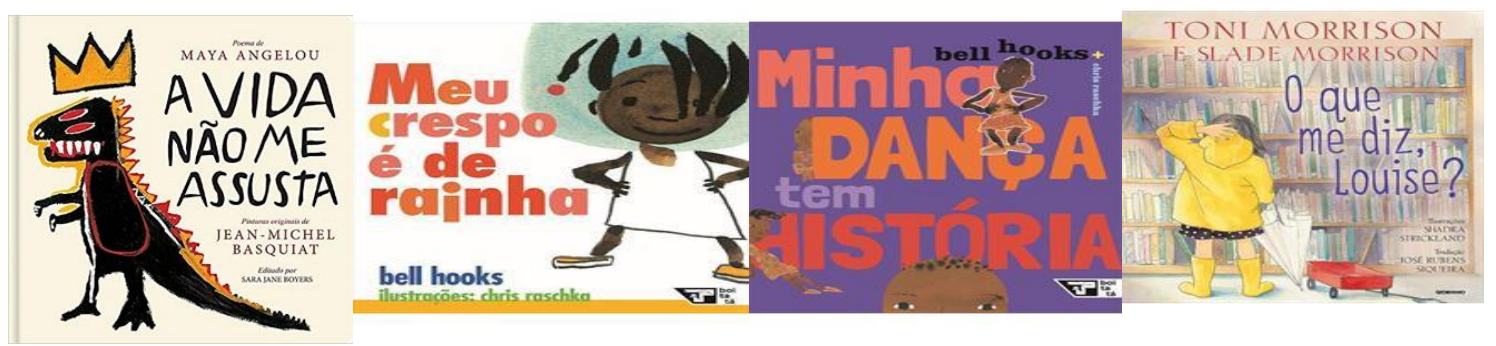


\section{Considerações finais: tardiamente...visíveis}

É possível afirmar que a presença de autoras negras tem florescido no mercado editorial brasileiro nos últimos anos, o que sem dúvida, é fruto de demandas e lutas históricas das mulheres negras, em diferentes frentes, para além dos nichos acadêmicos, sendo fundamental o engajamento das ativistas. É bastante perceptível também, uma distância temporal entre as publicações de obras seminais de autoria feminina negra: algumas chegaram ao Brasil 30 anos depois da primeira edição em língua inglesa. Tal discrepância nas temporalidades é verificada entre autores brancos ou origem europeia? As feministas brancas também são traduzidas tão tardiamente no Brasil? Quem consome o pensamento feminista negro de autoras nascidas nos Estados Unidos no Brasil? Onde estão as obras de autoras negras nascidas no Brasil e em outros países da América Latina? Tais autoras recebem a mesma atenção e tratamento por parte das editoras tidas como de maior porte? A escrita de mulheres negras, em diferentes gêneros, evidência diferentes maneiras de ser, sentir e resistir num mundo estruturado nos pilares das desigualdades de raça, gênero e classe.

\section{Referências}

ANGELOU, Maya. I Know Why the Caged Bird Sings. New York: Random House, 1969.

ANGELOU, Maya. A vida não me assusta. São Paulo: Caveirinha, 2018.

ANGELOU, Maya. Mamãe \& Eu \& Mamãe. Rio de Janeiro: Rosa dos Tempos, 2018.

CARNEIRO Sueli. Escritos de uma vida. São Paulo: Letramento, 2018.

COLLINS, Patrícia Hill. Feminist Thought: Knowledge, Consciousness, and the Politics of Empowerment. New York: Routledge, 1990.

Pensamento feminista negro. São Paulo: Boitempo, 2019.

DAVIS, Angela. Women, Race, \& Class. New York: Random House, 1981.

DAVIS, Angela.Abolition democracy: beyong empire, prisions, and torture. New York: Seven Stories Press, 2005.

DAVIS, Angela. Are the prisons obsolete? New York: Seven Stories Press, 2003.

DAVIS, Angela. Mulheres. Raça e Classe. São Paulo: Boitempo, 2016. 
DAVIS, Angela. Mulheres, Cultura e Política. São Paulo: Boitempo, 2017.

DAVIS, Angela.A Liberdade É Uma Luta Constante. São Paulo: Boitempo, 2018.

DAVIS, Angela. Uma autobiografia. São Paulo: Boitempo, 2019.

EVARISTO, Conceição. Olhos d'água. Rio de Janeiro: Pallas, 2014.

FELISBERTO, Fernanda e Ricardo Riso. "Cânone literário 'sob rasura': a urgência de políticas públicas para publicação/ divulgação/ circulação das literaturas negro-brasileira e periférica." Africanidades e Relações Raciais: Insumos para Políticas Públicas na Área do Livro, Leitura, Literatura e Biblioteca no Brasil. Org. Cidina da Silva. Fundação Cultural Palmares, 2014.

JACOBS, Harriet Ann. Incidents in the Life of a Slave Girl. Written by Herself. Boston: Published for the author, 1861.

JACOBS, Harriet Ann. Incidentes na vida de uma escrava: contados por ela mesma. Traduzido por Waltensir Dutra. Rio de Janeiro: Editora Campus, 1988.

JACOBS, Harriet Ann. Incidentes na vida de uma garota escrava, escritos por ela mesma. São Paulo, Aetia Editorial, 2018.

JACOBS, Harriet Ann. Incidentes na vida de uma menina escrava. São Paulo: Todavia, 2019.

Jesus, Carolina. Quarto de despejo. Rio de Janeiro: Francisco Alves, 1960.

GOMES, Nilma Lino. O movimento negro educador: Saberes construídos nas lutas por emancipação. Rio de Janeiro: Editora Vozes, 2017.

hooks, bell. Ain't I a woman? Black women and feminism. Cambridge: South End Press, 1981.

hooks, bell. Feminist theory : from margin to center. New York: Routledge, 1984.

hooks, bell. Talking Back: Thinking. Feminist - Thinking Black bell hooks. Sheba: London, 1989.

hooks, bell. Black Looks: Race and Representation. Boston: South End Press, 1992.

hooks, bell.Teaching to transgress. Education as the practice of freedom. New York: Routledge, 1994.

hooks, bell. Feminism is for Everybody. Cambridge: South End Press, 2000.

hooks, bell. Intelectuais negras. Estudos Feministas, v. 3, n. 2, p. 454-78., 1995. 
Ensinando a transgredir: a educação como prática de liberdade. São Paulo: Martins Fontes, 2013.

hooks, bell. O feminismo é para todo mundo: Políticas arrebatadoras. Rio de Janeiro: Rosa dos Ventos, 2018.

hooks, bell. Meu crespo é de rainha. São Paulo: Boitatá, 2018. b

hooks, bell. Erguer a voz. São Paulo: Editora Elefante, 2019.a

hooks, bell. Olhares Negros. Raça e Representação. São Paulo: Editora Elefante, 2019.b

hooks, bell. Anseios: raça, gênero e políticas culturais. São Paulo: Editora Elefante, 2019.c

hooks, bell. Eu não sou uma mulher? Mulheres negras e feminismo. Rio de Janeiro: Rosa dos Tempos, 2019.d

hooks, bell.Teoria Feminista: Da margem ao centro. São Paulo: Editora Perspectiva, 2019.e

hooks, bell. Minha dança tem história. São Paulo: Boitatá, 2019.f

KILOMBA, Grada. Memórias da Plantação: Episódios do racismo cotidiano. Rio de Janeiro: editora Cobogó, 2019.

MORRISON, Toni. O que me diz, Louise. Porto Alegre: Globinho, 2014.

NASCIMENTO, Maria Beatriz. Beatriz Nascimento, Quilombola e intelectual: possibilidade nos dias da destruição. Filhos da África, 2018.

RIBEIRO, Esmeralda. "A escritora negra e o seu ato de escrever participando." Criação crioula, nu elefante branco. Quilombhoje, 1987. 59-65.

RIBEIRO, Esmeralda. "37 anos de Cadernos Negros uma trajetória de resistência no Mercado editorial.” Africanidades e Relações Raciais: Insumos para Políticas Públicas na Área do Livro, Leitura, Literatura e Biblioteca no Brasil. Org. Cidina da Silva. Fundação Cultural Palmares, 2014.

SANTOS, Ynaê Lopes dos. História da África e do Brasil Afrodescendente. 1. Ed. Rio de Janeiro: Pallas, 2017.

SCHUCMANS, Lia. Famílias Inter-raciais: tensões entre cor e amor. Salvador, EdUFBA, 2018.

SMITH, Amanda Berry. An autobiography. The story of the Lord's dealings with Mrs.

Amanda Smith the colored evangelist. Chicago: Meyer \& Brother Publishers, 1893.

União dos Coletivos Pan Africanistas, Lélia González: primavera para as rosas negras, 2019. 
XAVIER, Giovana. Você pode substituir mulheres negras como objeto de estudo por mulheres negras contando sua própria história. Rio de Janeiro: Malê, 2019. 